\title{
Digital fingerprinting: New opportunities for solving crimes?
}

\author{
Abdullayev Rustam: r.abdullayev@tsul.uz, Orchid ID $\underline{\text { (0000-0001-8742-4815) }}$ \\ Ganiyev Otabek: o.ganiyev@tsul.uz, Orchid ID (0000-0001-9835-8817)
}

Tashkent state university of law

\begin{abstract}
High technologies at the present stage of development of the world community have penetrated into all spheres of human activity. Considering the issue of digital methods of crime investigation, of course, forensic experts are faced with problems of their effectiveness. Today, most Western countries in the investigation of crimes use fingerprint examination, using technology, thereby reducing the time of investigation, ensuring efficiency. And yet, not all forensic specialists use these techniques when taking fingerprints, relying on the reliability and the usual proven practice of the classical method of fingerprinting. As you know, in the countries of the post-Soviet space, this method was used on the basis of scientific approaches developed by such scientists as E. Henry, A. Bertillon, G. Gross, E. Locard, etc. For example, the work of E. Henry formed the basis for fingerprint registration, since the scientific approach to the biological process of damage and restoration of the epidermis during the investigation of a crime, it is necessary to attach special importance, since papillary lines also have the property of recoverability. If the dermis is damaged, then the pattern is not restored in such an area. But the scars that appear at the same time, the scars themselves become the hallmarks of the pattern. For a century, forensic scientists have studied the sweat marks of handprints for identification, since each fingerprint is different. In this analytical article, the authors made an attempt to conduct an analytical review of the implementation practices of digital fingerprinting in different countries and study the extent to which the effectiveness of its application is possible.
\end{abstract}

Keywords:

fingerprinting, investigation, fingerprints, epidermis, forensic examination, fingerprint card, papillary pattern, forensic science Article Received: 18 October 2020, Revised: 3 November 2020, Accepted: 24 December 2020

\section{Introduction}

Fingerprinting is a method of identification (identification) of a person by fingerprints, based on the uniqueness of the skin pattern. Forensic science was the first and most important field of application for fingerprinting and remains so. In criminal proceedings, fingerprinting occupies a special place in the detection and disclosure of a crime. For a long time, fingerprint examination has been used by the bodies of inquiry and investigation.

It is difficult to imagine investigating crimes without conducting expert examinations to create an evidence base. To clarify the circumstances, firstly, to find traces of the crime and, secondly, to make identification, which in turn contributes to justice.

Forensic science in the practice of crime investigation highlights the theory that most traces of papillary patterns are formed by transferring sweat substance from the finger (palm) to the traceperceiving surface. In some cases, when the hands are contaminated with foreign substances (for example, blood, damp paint, oil, etc.), these substances are also transferred from the hands to the trace-sensing surface in the form of traces of papillary patterns. According to the mechanism of formation, such traces are classified as layering traces.

Traces of papillary patterns can also form due to the detachment of a fragile surface layer from objects (for example, dust, soot, wet paint, grease, etc.). Handprints are used more frequently in forensics than other handprints. This is due to the fact that criminals leave traces of papillary patterns when committing a crime more often than other traces [1].

In modern forensics, several methods are used to determine fingerprints. Most often, experts use the following aids: fingerprint powder; 
fluorescent powder; iodine vapors.

Of course, there are others, at the moment more than twelve means are known that allow you to take prints from different surfaces. The choice of technology by an expert depends on them. In order to identify a person's identity, the investigator assigns a fingerprint examination of fingerprints. The work of experts in this direction certainly requires a high qualification of an expert for further effective investigation of crimes. I would also like to note about the possibility of using another type of fingerprinting. In case of insufficient identification features characterizing the finger pattern, the research method is ejoscopy. Its essence lies in the fact that with a microscopic increase in papillary lines by 20-25 times, irregularities in their edges in the form of protrusions, depressions, bends, etc. are observed, which serve as additional identification signs. Traditional techniques, methods and means of registering and working with handprints are being replaced by modern, more effective ones, and there is reason to believe that in the future, fingerprinting will become an even more powerful weapon in the hands of law enforcement agencies fighting crime.

\section{Methods}

The current work for the our article in the form of review is based on comparative data analysis of the implementation digital forensic. The informational source for the analytical work is taken from the researchers results made in the field of fingerprint forensic. This paper aims to represent the difference between the digital forensic and its effectiveness without empirical studies, but introduce the actual approaches to use digital fingerprint in the crime investigation process.

\section{Discussion}

According to some legal researchers, there are some mistakes in practice. So, S. Samishchenko, V. Ivashkov express the opinion that when a person is identified by the images of papillary patterns containing 7 or more features, a random coincidence of other people's prints is practically impossible due to the properties of the object itself. However, an analysis of the practice of experts showed that identification errors are encountered. At the same time, it was established that the main reason for the erroneous conclusions of the experts with low information content of the traces is the "human factor", i.e. expert error. [2].

An example of a mistaken identification by a fingerprint expert is the Mayfield case. On March 11, 2004, several bombs exploded on commuter trains in Madrid, eventually killing 191 people and wounding over 200 . The fingermarks left on a bag with detonators connected with the attack were believed to match the fingerprints of Brandon Mayfield. This fingerprint identification was made by three members of the FBI Laboratory's Latent Print Unit. After Mayfield had been detained for two weeks, the Spanish National Police arrested an Algerian national whom they identified as the source of the fingermarks. He turned out to be 'a better match' than Mayfield [5]. The above studies show that findings of forensic investigations can be interpreted differently) [3].

A lot of scientific and research works both in the CIS countries and abroad have been devoted to the issues of eliminating the errors of experts and improving the methods of examining handprints. Another big problem is the gross violation by experts of the method of working with handprints. It consists in the fact that the technological chain of methodological techniques for working with handprints, starting from their detection at the scene of the incident and until the formation of the conclusion of a fingerprint examination by experts, is not carried out in full. As a result, the participants in the criminal process have doubts that the trace, on the results of the study of which the positive conclusion of the fingerprint examination is built, is precisely the trace that was found at the crime scene. That is, the methodological procedure for working with material evidence is violated, which can guarantee the relevance of the trace to the event of the crime. At the crime scene, most often there is a disorderly arrangement of tracks. So while you may have a unique crime scene fingerprint and 
global databases, including the European Union's EURODAC full of unique fingerprints, it can be difficult to compare them to find a suspect. "It's not about the system, it's about the people," says Goodwin, the former head of the United Kingdom's fingerprint bureau, who has also been contracted with the UN Office on Drugs and Crime and the International Criminal Court in The Hague. [4] Crime scenes can be messy places. So while you may have a unique fingerprint from a crime scene, and global databases - including the European Union's EURODAC - stacked full of unique prints, comparing them to find a suspect can be tough. "It's not the system, it's humans," says Goodwin, a former head of a United Kingdom Fingerprint Bureau who has also been contracted by the United Nations Office on Drugs and Crime and the International Criminal Court in The Hague.

\section{Modern fingerprinting.}

Digital fingerprinting, also known as electronic fingerprinting, is a modern approach to creating images of fingerprints that can be used for identification purposes in a number of settings. This type of resource can be used to strengthen security measures in companies, government buildings and other physical locations, as well as to create more effective copyright protection and identify criminals involved in a specific crime. Unlike older fingerprinting techniques, modern digital fingerprints are not subject to degradation and can be matched against various electronic records in a very short time, perhaps even a few seconds in some applications [5].

While technological advances affect all aspects of life, their impact on the crime investigation process is not surprising. One factor that directly influences the success of fingerprint professionals is the equipment used in the data collection and evaluation procedures. As the crime scene becomes more complex, the amount of equipment used increases and more specialized products are needed [6]. While technological advances affect every aspect of life, their impact on the CSI process is not surprising. One of the factors that directly affect the success of fingerprint experts is the equipment used in data collection and evaluation procedures. As the crime scene becomes more complex, the number of equipment used increases, and more specialized products are needed [7].

So, for example, in the Russian Federation, the used system AFIS PAPILLON provides maximum automation of the registration of fingerprint information in the database. Fingerprints of the ADIS PAPILLON database store images of rolled prints of 10 fingers and prints of the palms of registered persons, photographs of their appearance and special features, demographic and other accompanying information. All fingerprints are automatically encoded. The technology of operational checks was developed in 2001, was first successfully applied in 2005 and has been widely used by the Ministry of Internal Affairs of Russia since 2009. Operational checks are carried out to identify persons suspected of committing crimes, hiding under forged documents, declared on the Federal wanted list, to establish the identity of citizens who are unable to report themselves, as well as in relation to forced migrants, migrants, persons crossing the border of the Russian Federation and others.

Today, fingerprint examination is the most popular type, it is carried out in the process of investigating almost all types of crimes. And, despite more than a century of existence, fingerprinting not only has not lost its importance in solving and investigating crimes, but has significantly expanded its capabilities over the past decades. Achievements of science and technology, to one degree or another, are reflected in the process of expert research of papillary patterns. Today, according to the traces of the fingers, namely the sweat substance, not only the blood group of the person who left the trail is established, but also this person is identified (biological identification) [8].

Currently, there is an established classification that provides for ten classes of forensic examinations, but it is not final and can 
change both in the number of classes and in the content of most of them. At the same time, it should be noted that when classifying, scientists take into account not only and not so much expertise in their procedural understanding, but the very directions of expert research, determined by the "mother" sciences. When characterizing the place of fingerprinting examinations in the modern classification, it is necessary to take into account all the quantitative and qualitative characteristics of the directions of work with papillary patterns, since the actual fingerprint examination is only a procedural form of the work that is carried out with papillary patterns [9].

Currently, the internal affairs bodies of Kazakhstan have also created a centralized automated fingerprint system "Papilon" with remote access, which allows checking handprints from the scenes of unsolved crimes in the central database of the Ministry of Internal Affairs in real time [10]. With the help of fingerprinting records, criminologists ensure that crimes are solved at the level of $9 \%$ of the total number of registered crimes, or about 12 thousand crimes per year.

Hundreds of crimes, including crimes against the person: murder, robbery, robbery, rape, deliberate infliction of grievous bodily harm, are promptly solved in Uzbekistan with the help of AFIS "Sonda" every year. Many of these solved crimes are, possibly, someone's saved later in life.

The automated fingerprint identification system (AFIS) "Sonda" is widely used by employees of forensic departments to create and maintain an electronic database of fingerprints, fingerprints and palms seized from crime scenes. The system is designed to carry out all types of fingerprint and palmprint identification, such as establishing the identity of criminals who left handprints at a crime scene, identifying unidentified corpses, including those killed as a result of terrorist attacks, catastrophes or natural disasters, identifying persons who are in the international wanted, establishing the involvement of a particular person in the commission of criminal acts.
Automatic Fingerprint Identification System consists of two main types of searches, namely ten-print search (rolled and slap impressions???) and a latent search. Due to technological advancements, the ten-print identification process of AFIS is fully automated with improved accuracy and throughput, leading to wide deployment in law enforcement agencies [11].

Fingerprint matching is computationally expensive. Some of the larger AFIS vendors deploy dedicated hardware, while others use software to achieve the appropriate speed and bandwidth. In general, it is desirable to have at least a two-step search. In the first step, the global characteristics of the fingerprint are usually used, and in the second step, the comparison of small details. In either case, search engines return results with some numerical measure of the likelihood of a match ("score"). When searching with ten fingerprints using the search threshold parameter, to improve accuracy, there should rarely be more than one candidate if the database does not have multiple records from the same candidate.

Many systems use broader searches to reduce the number of missed identifications, and this search can return one to ten possible matches. Hidden fingerprint searches often return many (often fifty or more) candidates due to the limited and low quality of the input data. The confirmation of candidates proposed by the system is usually performed by a specialist in the judicial systems. However, in recent years, "light off" or "automatic confirmation" algorithms have produced "identified" or "unidentified" responses without the human operator looking at the prints, provided the conformance score is high enough. "Light off" or "automatic confirmation" is often used in civil identification systems, and is also increasingly used in criminal identification systems [12].

\section{Conclusion}

Studying the practice of applying the study of fingerprints, in our opinion, there are certainly the same approaches to the study of papillary 
patterns, but at the same time, the methodology has its own differences.

One cannot but agree with the opinion that the effectiveness and efficiency of international cooperation in the exchange of forensically significant information on traces and prints of hands largely depends on the improvement of the regulatory framework, existing information technologies, both in the Russian Federation and in the CIS countries, as well as competent work of forensic experts with traces and prints of hands, which will make it possible to disclose committed crimes as soon as possible [13].

As we see that modern technology is becoming more convenient, a lot of work will transferred to the automatic methods. Nevertheless, the final word will remain with the human. Much has changed in recent years. For a hundred years, fingerprints were taken with ink and paper, and in triplicate. The sample of fingerprint was remained at the police station. Today, many police stations have fingerprint scanning systems where a suspect only needs to put a finger on the scanner and the system does the rest. The scanned image is transferred to a computer for classification and analysis, up to the last step, which is manual verification. What previously took several hours can now be done in minutes. However, it is worth noting that such a rapid development of technologies, to a large extent, reduces the value of the experience and vision of specialists. It is still impossible to say how this will affect the process and tasks of training fingerprinters in the future.

\section{REFERENCES:}

[1] Arslan et al., Vol.8, No.4, pp.88-113, INTERNATIONAL JOURNAL OF INFORMATION SECURITY SCIENCE

[2] Avramenko OI ROLE OF APPLICATION OF IMAGE PROCESSING METHODS IN THE PRODUCTION OF FORENSIC DACTYLOSCOPIC EXPERTISE / OI Avramenko // International scientific research journal. - 2019. - No. 10 (88) Part
2. - P. 56-58. doi: $10.23670 /$ IRJ.2019.88.10.0341

[3] V.F. Vasyukov, I.V. Modern possibilities of forensic fingerprinting. Innovative approaches to the implementation of expert methods // Law and Law. 2019. No. 2. Url: https://cyberleninka.ru/article/n/sovremenn ye-vozmozhnosti-kriminalisticheskoydaktiloskopii-innovatsionnye-podhody-krealizatsii-ekspertnyh-metodik (дата обращения: 20.01.2021).

[4] Vesnina S.N, Neustroeva A. V. Stepanyugin K.V. PROSPECTS AND POSSIBILITIES OF APPLICATION OF MODERN MEANS AND METHODS OF FINGERPRINTING IN EXPERT PRACTICE/ International Center for Scientific Cooperation "Science and Education" Penza-2019

[5] Elmarije K. van Straalen, Christianne J. de Poot, Marijke Malsch, Henk Elffers,

[6] The interpretation of forensic conclusions by criminal justice professionals: The same evidence interpreted differently,Forensic Science International, Volume 313, 2020, https://doi.org/10.1016/j.forsciint.2020.110 331

[7] Kolesnikova A. Yu. ESSENCE OF DACTYLOSCOPIC EXPERTISE AND ITS MAIN AREAS OF RESEARCH // INTEGRATION OF SCIENCE, SOCIETY, PRODUCTION AND INDUSTRY. - 2019.- P. 154.

[8] Nancy Singla, Manvjeet Kaur, Sanjeev Sofat, Automated latent fingerprint identification system: A review,Forensic Science International, Volume 309, 2020, 110187, ISSN 03790738,https://doi.org/10.1016/j.forsciint.202 0.110187

[9] Yakovleva A.S. Яковлева A. C. The possibilities of the international cooperation to exchange important fingerptint forensic information. Opportunities for international cooperation 
in the exchange of forensically significant information on the traces and prints of hands // Forensic expert. - 2016. - №. 4. C. 23.

[10] Khakberdiev Abdumurad types, classifications and systems according to the structure of the criminal dramatization «Хуқуқий тадқиқотлар журнали» 3(5) 2020.

\section{Uncited references:}

[11] https://kemerovobarberwanted.ru/verberbernar/otpechatki-palcev-v-kriminalistikekak-nazyvaetsya-ulika-kotoraya-vsegda-s/

[12] https://wiselawyer.ru/poleznoe/23200nekotorye-problemy-sovremennojdaktiloskopii

[13] https://www.netinbag.com/ru/internet/what -is-digital-fingerprinting.html

[14] https://ru.qaz.wiki/wiki/Automated_finger print_identification 